\title{
RECUPERAÇÃO DE INFORMAÇÃO NA IDENTIFICAÇÃO DE NÃO GARANTIA AUTOMÁTICA DE DIRETOS DE CRIANÇAS E ADOLESCENTES
}

\author{
RECUPERACIÓN DE INFORMACIÓN EN LA \\ IDENTIFICACIÓN DE NO GARANTÍA AUTOMÁTICA DE \\ DERECHOS DE NIÑOS Y ADOLESCENTES
}

\author{
Yeda Maria Macedo Romanini ${ }^{\mathrm{a}}$ \\ Deborah Ribeiro Carvalhob
}

\begin{abstract}
RESUMO
Introdução: Avaliar o quanto a população não tem garantido, de forma automática, o direito à saúde exige consulta às Jurisprudências e Acórdãos, tendo em vista a não disponibilidade de dados sistematizados. Objetivo: Elencar as situações de não garantia automática do direito à saúde das crianças e adolescentes associados à Medida Protetiva e Socioeducativa. Método: Para a busca por Jurisprudências e Acórdãos foi adota a estratégia de Recuperação de Informação e a partir destes textos foi construída uma base de dados. Resultado: Foram adotados 11 termos para a busca, resultando em 502 textos referentes a Jurisprudências e Acórdãos. Foram elencadas 25 variáveis para a construção da base de dados. A partir da análise é possível perceber que as situações de não garantia automática do direito à saúde, que mais se destacam são: assistência psicológica/ psiquiátrica; inclusão em programas de auxílio e orientação à família, à criança e ao adolescente; e tratamento médico. Conclusão: Essas demandas sinalizam que as crianças e os adolescentes se encontram em alguma situação de risco à saúde. Fato esse que não deveria acontecer, já que o direito à saúde é estabelecido por Lei, não havendo necessidade de demandas para esses pedidos.
\end{abstract}

Descritores: Criança e Adolescente. Direito à Saúde. Recuperação de Informação.

\footnotetext{
${ }^{a}$ Mestre em Tecnologia em Saúde pela Pontifícia Universidade Católica do Paraná (PUC). Email: yeda.adv@hotmail.com

${ }^{\text {b }}$ Doutora em Informática Aplicada pela Pontifícia Universidade Católica do Paraná e Doutora em Computação de Alto Desempenho pela Universidade Federal do Rio Janeiro. Professora do Programa de Pós-Graduação em Tecnologia Aplicada em Saúde da Pontifícia Universidade Católica do Paraná (PUC). E-mail: ribeiro.carvalho@pucpr.br
} 


\section{INTRODUÇÃO}

Crianças e adolescentes são considerados sujeitos em condição peculiar de desenvolvimento que requerem atenção especial e prioritária por parte do Sistema de Garantia de Direitos. Aliado ao fato de que quando esta população se encontra em regime de Medida Protetiva ou Socioeducativa existe a preocupação de que condições sejam oferecidas para que possam retornar ao convívio social.

O Sistema de Garantia de Direitos (SGD) recebe atenção especial desde a Constituição de 1988 e promulgação do Estatuto da Criança e do Adolescente (ECA), em 1990, como parâmetro para políticas públicas voltadas às crianças e adolescentes. É formado pela integração e a articulação entre o Estado, as famílias e a sociedade civil como um todo, com a finalidade de garantir o cumprimento da Legislação (ECA, 1990).

A proteção à saúde denota um sentido amplo, ainda mais após a vinda do ECA que constitui diversas medidas de promoção, proteção e atenção, de acordo com as suas características, possibilitando 0 crescimento e 0 desenvolvimento adequados para uma vida adulta saudável (ROSA, 2013).

A estrutura do SGD conta com três eixos estratégicos de atuação:

a) Defesa - se encontra o Conselho Tutelar, o qual funciona como um guardião, ao observar e encaminhar em campo os casos de violações dos direitos que podem vir a ocorrer com crianças e adolescentes. Aliado ao Conselho Tutelar se encontra o promotor do Ministério Público, o qual age em casos de abusos dos direitos;

b) Promoção - responsáveis por executar o direito, transformá-lo em ação. Esse eixo detecta a organização da sociedade civil organizada;

c) Controle - destaque aos Conselhos de Direitos, espaço de participação da sociedade civil para a construção democrática de políticas públicas.

Embora haja o amparo e a organização desses eixos, a avaliação do quanto esta população está tendo os seus direitos garantidos não constitui atividade trivial. Ainda mais no que tange o direito à saúde, tendo em vista a 
disponibilidade de dados sistematizados que apontem situações e condições da não garantia.

A sistematização destes dados se torna importante, pois sentenças de magistrados são proferidas sob diversas formas de escrita (CONSTÂNCIO; CARVALHO; TSUNODA, 2017). Aliado ao fato de que facilitar a ação do Poder Judiciário em "desafogar" suas prateleiras para que crianças e adolescentes não se tornem reféns do tempo de duração de um processo.

Uma alternativa para minimizar a dificuldade imposta pela não disponibilidade de dados sistematizados, é o levantamento a partir de Jurisprudências e Acórdãos que representem demandas referentes a direitos não obtidos naturalmente. Porém identificar as Jurisprudências e Acórdãos que tratem desta natureza de demanda apresenta uma dificuldade implícita dada o volume de textos disponível.

Se por um lado existe a Lei que tudo protege, por outro tem-se a não garantia automática do direito à saúde. Esse fato pode ser evidenciado a partir das Jurisprudências e Acórdãos expedidos pelos Tribunais Superiores, os quais evidenciam a vivencia das crianças e dos adolescentes (ROSA, 2013).

$\mathrm{Na}$ Legislação, o conceito de Acórdãos se encontra no art. 204, CPC, em que "representa o julgamento colegiado proferido pelos tribunais". Jurisprudências representam o conjunto de decisões judiciais que apontam tendências a serem seguidas por decisões posteriores. Vale ressaltar ainda, que para cada Jurisprudência existe o respectivo Acórdão, possibilitando uma visão geral dos fatos durante o processo (GRINOVER; WATANABE, 2012).

Dado o fato do volume disponível de Jurisprudências e Acórdãos ser grande, bem como a inexistência de um padrão a adotado pelos magistrados para a construção do conteúdo é importante adotar um critério a partir do qual estes textos sejam selecionados. Uma alternativa para otimizar esta tarefa é a adoção da Recuperação de Informação mais especificamente, a identificação de termos que orientem esta busca, a qual é realizada pela Recuperação de Termos (GOMES et al, 2017).

A Recuperação de Termos está inserida na área de Recuperação de Informação, a qual representa um campo da Ciência da Computação que trata 
das formas para efetivar buscas em um sistema computacional, objetivando ampliar a relevância dos resultados frente à expressão que orientou a busca (FRAKES; BAEZA-YATES, 1992; SILVA; SANTOS; FERNEDA, 2013).

A Recuperação de Termos representa uma das etapas da Recuperação de Informação de tem por objetivo identificar e destacar, de forma automática as informações contidas em documentos, baseada em uma decomposição do espaço vetorial de termos de índice (LOPES, 2002; ZHOU; SMALHEISER; YU, 2006).

Entre as alternativas para esta Recuperação de Termos encontra-se o PORONTO (ZAHRA; CARVALHO; MALUCELLI, 2013). Apesar de a ferramenta ter como objetivo a construção de ontologias, dentre as etapas intermediárias é disponibilizada a identificação dos termos (CUBAS et. al, 2017).

Este artigo apresenta uma proposta metodológica para elencar as situações de não garantia automática do direito à saúde das crianças e adolescentes associados à medida Protetiva e Socioeducativa a partir de Jurisprudências e Acórdãos, com o apoio da Recuperação de Termos.

A contribuição social desta pesquisa consiste na instrumentalização dos gestores envolvidos com crianças e adolescentes associados à Medida Protetiva e Socioeducativa, mediante a disponibilidade de um conjunto de dados criado com base nas Jurisprudências e nos Acórdãos. Permitindo assim um melhor entendimento desta realidade.

Já como contribuição científica tem-se a oportunidade de testar e utilizar uma tecnologia, baseada na Recuperação de Informações, especificamente na Recuperação de Termos, que pode facilitar a busca por textos jurídicos de diversas naturezas.

\section{METODOLOGIA}

Esta pesquisa se caracteriza como qualitativa, pois assume um conjunto de diferentes técnicas interpretativas descrevendo os componentes de um sistema complexo de significados. Tem por objetivo traduzir e expressar 0 sentido dos fenômenos do mundo social; trata-se de reduzir a distância entre 
teoria e dados, entre contexto e ação (VAN MAANEN, 1979, p.520).

Bem como quantitativa, pois a partir dos dados coletados foi construída uma base de dados que possibilitou a extração de informações que contribuíram para um melhor entendimento da realidade investigada.

A pesquisa foi estruturada em 11 etapas (Figura 1). Inicialmente foi definido o conjunto preliminar de termos para orientar a busca por Jurisprudências e Acórdãos (CONJ1). O critério para esta definição foi a aderência à prática jurídica, a partir de indicação por professores da área, bem como a de artigos relacionados. Os termos que compõem o CONJ1 são: "Medida Protetiva", "Medida Socioeducativa", "Risco à Saúde", "Tratamento", "Saúde e ECA".

$\mathrm{Na}$ etapa 2 foram selecionados os sites, referentes à região Sul, ou seja, dos Tribunais de Justiça do Paraná (TJPR), www.tjpr.jus.br, Tribunal de Justiça de Santa Catarina (TJSC), www.tjsc.jus.br, e Tribunal do Rio Grande do Sul (TJRS), www.tjrs.jus.br para busca de textos. O Superior Tribunal de Justiça (STJ) e o Supremo Tribunal Federal (STF) não foram objetos de pesquisa por terem abrangência nacional.

$\mathrm{Na}$ etapa 3 foram estabelecidos os critérios para a seleção dos textos (TEXTOS1) retornados a partir dos termos referentes ao CONJ1, a saber:

- Retratar apenas questões de saúde referentes às crianças e adolescentes com vinculação ao cumprimento de Medida Socioeducativa, Protetiva e Saúde;

- Ter sido publicado entre janeiro e dezembro de 2013.

Vale destacar que foram eliminados textos em duplicata.

Para potencializar o conjunto de termos (etapa 5) a ser adotado para a busca por Jurisprudências e Acórdãos, foi adotada a ferramenta PORONTO (ZAHRA et al, 2013), para a Recuperação de Termos. Porem para tal, é imperativo pré-processar o conjunto de textos (TEXTOS1) de tal forma que atenda à exigência de layout da ferramenta (etapa 4).

A justificativa pela adoção da ferramenta PORONTO (ZAHRA et al, 2013), se deve ao fato de além de atender à necessidade de Recuperação de Termos, também apresenta facilidade de operação (GOMES et al, 2017).

Como saída da etapa 5 , foi obtido um novo conjunto de termos (CONJ2). 
Para avaliar a pertinência ou não de cada um dos termos (CONJ2) foi realizada uma avaliação manual (etapa 6), priorizando a permanência daqueles termos que melhor se aproximassem do quesito saúde da criança ou do adolescente, gerando assim o CONJ2Limpo (etapa 7). Esta etapa manual ainda é necessária dada a não disponibilidade de busca semântica, fundamentada por uma ontologia jurisprudencial no Brasil (CONSTÂNCIO; CARVALHO; TSUNODA, 2017).

A partir da etapa 8 foi obtido o conjunto de termos (CONJ3) que efetivamente orientou a busca por Jurisprudências e Acórdãos que permitissem atingir o objetivo da pesquisa (TEXTOS2). O CONJ3 foi composto pelos termos constantes nos CONJ1 acrescidos dos termos do CONJ2Limpo.

Vale destacar que a partir do conjunto TEXTOS2, foi realizada avaliação manual sobre a pertinência ou não de cada um dos textos, gerando assim o conjunto TEXTOS3, mantendo os mesmos critérios de seleção para a construção TEXTOS1.

Por fim, o conjunto TEXTOS3 serviu de base para a extração dos dados (etapa 11) que compuseram a sistematização em atendimento ao objetivo desta pesquisa.

Figura 1: Fluxo das etapas para a busca e sistematização de Jurisprudências e

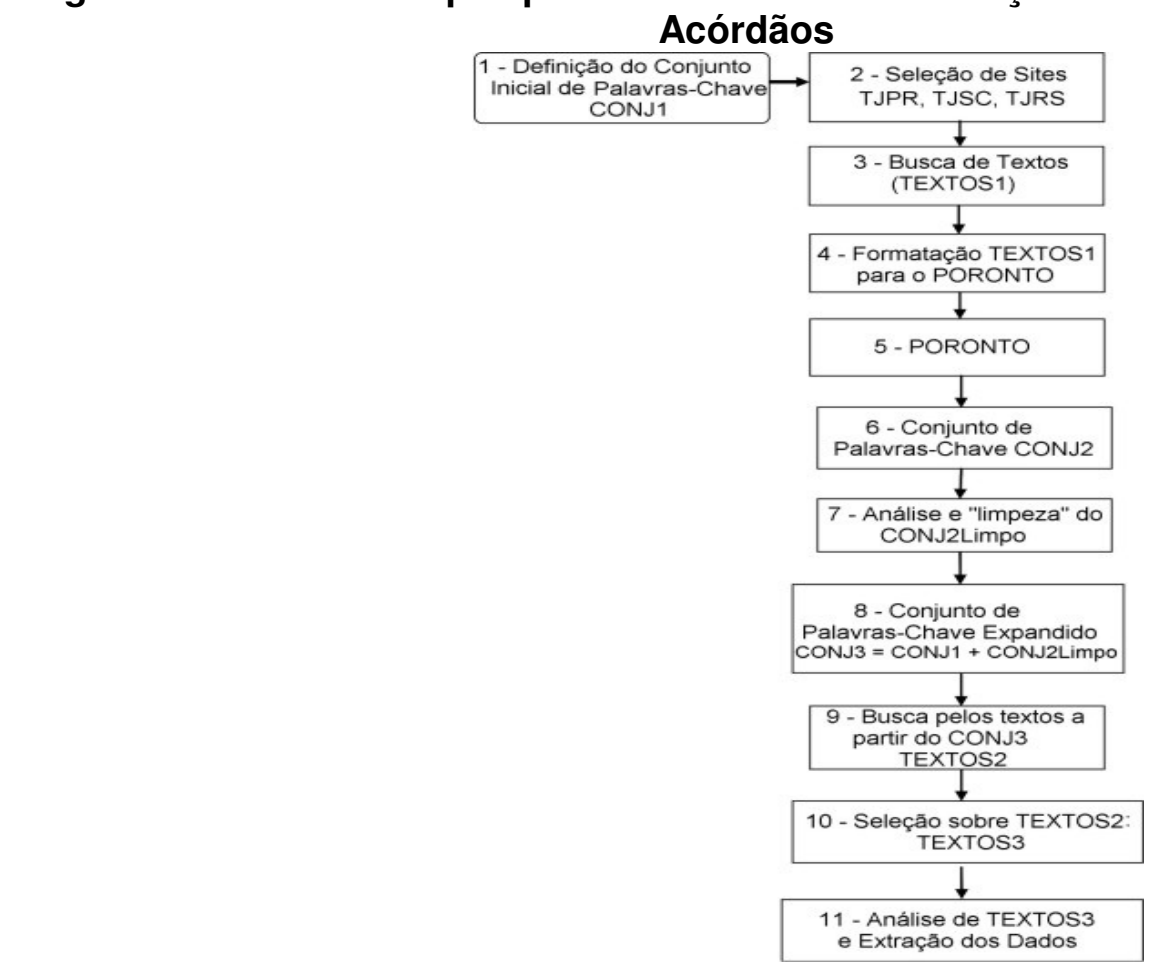

Inf. Inf., Londrina, v. 23, n. 1, p. $132-149$, jan./abr. 2018

http://www.uel.br/revistas/informacao/ 
Como produto da etapa 11 foi construída uma base de dados considerando 25 variáveis, a saber:

1. Número - número sequencial para organização dos textos;

2. Palavra-chave - termo que orientou a busca por Jurisprudências e Acórdãos;

3. Unidade da Federação: Paraná, Santa Catarina ou Rio Grande do Sul;

4. Data final - data na qual o processo foi julgado;

5. Publicação - data de publicação do processo no Diário Oficial da União;

6. Dias - intervalo em dias entre as datas Finais e da Publicação;

7. Privação de Liberdade Anterior - retrata qual era a situação em que a criança ou adolescente se encontrava quando estava aguardando o julgamento. Ou seja, se este estava em abrigo, sob a guarda dos pais ou responsáveis. Este item de dado está elencado por meio de texto, trazendo a forma de abrigo ou ainda o termo "não encontrado", que significa que não consta essa informação no texto selecionado;

8. Privação de Liberdade Atual - modalidade de Privação de Liberdade quando do processo. É sistematizada por meio de texto, trazendo a forma de abrigo que a criança e o adolescente se encontram, por exemplo, "abrigo com tratamento psicológico". Ou ainda, o termo "não encontrado", que significa que não consta a informação na Jurisprudência nem nos Acórdãos;

9. Privação de Liberdade Pleiteada - forma de Medida Socioeducativa que está sendo pleiteada. Em geral, o que motiva a solicitação da mudança da espécie de Privação de Liberdade decorre da possibilidade da anterior representar alguma situação de Risco à Saúde da criança e do adolescente. Este item de dado está elencado por meio de texto, trazendo a forma de abrigo onde a criança e o adolescente precisam estar, para que tenham o seu direito à saúde assegurado. Ou, ainda, o termo "não encontrado", que significa que essa informação não consta na Jurisprudência nem nos Acórdãos

10. Manutenção da forma de privação da liberdade anterior/atual - se a forma de privação de liberdade foi mantida entre a situação anterior e a atual;

11. Manutenção da forma de privação da liberdade atual/ pleiteada - se a forma de privação de liberdade foi mantida entre a atual e a pleiteada 
12. Motivo Privação de Liberdade - motivo pelo qual a criança ou o adolescente se encontram em Privação de Liberdade. Este item de dado está elencado por meio de texto, trazendo a principal infração cometida pela criança e pelo adolescente, por exemplo, furto;

13. Situação de privação de liberdade - como a criança ou o adolescente se encontrava antes da sentença (privação de liberdade ou não). As variáveis 7, 8 e 9 apontam qual é a espécie de privação de liberdade (se estava em abrigo, sob custódia dos pais, se precisava de acompanhamento médico...). A variável 13 apenas aponta se estava em Privação de Liberdade ou não;

14. Tratamento à saúde pleiteado - qual é o tratamento que a criança ou adolescente demanda. Por exemplo, acompanhamento psicológico ou ainda tratamento para drogadição. Este item de dado está elencado por meio de texto, trazendo o tratamento que a criança ou o adolescente precisa enquanto estiver em regime de Privação de Liberdade;

15. Resultado - em virtude de o Processo já estar em fase de Acórdão e Jurisprudência, ele já passou por uma série de recursos. A fase do resultado é para verificar se a resposta do juiz continua sendo a mesma no decorrer do Processo ou se a Sentença se modifica. Este item de dado está elencado por meio de texto, trazendo ou não a mudança da resposta do juiz. Caso a resposta não seja modificada, classifica-se como "não reformado" ou "não provido"; caso haja reforma, apropria-se o texto reformado, por exemplo, "internação - não se comprovou a reincidência";

16. Primário/ Reincidente - se o ato infracional foi realizado pela primeira vez, é primário, caso já o tenha realizado outras vezes, é considerado reincidente;

17. Peça - Recurso ou Mandado de Segurança;

18. Fundamentação Legal - Lei que sustenta a defesa;

19. Outros Direitos Ofendidos - algum outro direito não garantido pela criança ou adolescente em cumprimento de Medida Socioeducativa, como por exemplo, coação moral. Este item de dado está elencado por meio de texto, trazendo o termo "Princípio da Integridade da Pessoa Humana", no caso em que, no flagrante, a criança ou $\mathrm{o}$ adolescente sofreu ato demasiadamente 
repressivo. Caso não tenha outros direitos ofendidos, emprega-se o termo "Não há" no quadro;

20. Sentença - Ordem Denegada ou Concedida - este item de dado demonstra se a resposta do juiz foi negativa, a qual atende pelo termo "Denegado", ou a resposta do juiz foi afirmativa e então atende pelo termo "Concedido"; está elencado por meio de texto;

21. Princípio da Insignificância - como o contexto de Leis brasileiras se respalda em que "todos somos inocentes até que se prove o contrário", há a possibilidade de verificar se no Processo houve a insignificância dos atos dessas crianças ou adolescentes. Este item de dado está elencado por meio de texto; traz o termo "não há", caso não tenha sido ferido o referido princípio, ou, ainda, se encontrará sob o termo "há" se houver o Princípio da Insignificância;

22. Instância - qual foi o Tribunal competente para realizar a Jurisprudência e os Acórdãos analisados. A Instância será elencada por meio de texto, trazendo o Tribunal que está responsável pelo determinado processo. Este item de dado é elencado por meio de texto, trazendo os termos TJ/PR, TJ/SC, TJ/RS;

23. Constrangimento llegal - se houve ou não o constrangimento da criança ou do adolescente. Este item de dado é elencado por meio de texto, trazendo o termo "há", caso tenha constrangimento ilegal, ou ainda "não há", caso não haja constrangimento ilegal;

24. Risco de Morte - se a criança ou adolescente se encontra sob o risco de saúde ou vida. Há de se impor uma Medida Protetiva para retirá-lo desse meio. Este item de dado contém as Medidas adotadas;

25. Grupo etário - criança ou adolescente.

Vale destacar os dados referentes as 25 variáveis contidas na base de dados foram extraídos e padronizados. Para a extração de informações foi adotado o critério de agrupamento dos valores de domínio para as seguintes variáveis: Palavra-chave, tipo Privação de Liberdade Anterior, Tipo Privação de Liberdade Atual, Tipo de Privação de Liberdade Pleiteada.

O critério adotado para o agrupamento foi a identificação das três/quatro maiores frequências relativas entre os valores de domínio da variável em questão. Uma vez identificados estes valores de domínio os demais foram 
agrupados sob o "rótulo" outros. Esta estratégia se justifica, pois representam os itens de maior relevância para a extração de tabelas cruzadas (VIEIRA, 2008)

Para o levantamento das situações de não garantia automática do direito à saúde pelas crianças e adolescente associados à Medida Protetiva e Socioeducativa foram extraídas estatísticas a partir da base de dados envolvendo, motivação da demanda, fundamentação legal a partir do artigo da legislação, resultado e sentença.

\section{RESULTADOS}

Como conjuntos originais foram identificados 37.933 textos. Após análise e limpeza (foram retirados textos que se encontravam em segredo de justiça e os não aderentes) a busca de textos (TEXTOS1) resultou em 433 textos. A partir dos critérios de seleção, representando $0,64 \%$ do conjunto original. Lembrando que o conjunto original é formado a partir das seguintes palavraschaves: Medida Protetiva, Medida Socioeducativa, Risco à Saúde, Saúde ECA, Tratamento Saúde.

Como resultado da Recuperação de Termos a partir da ferramenta PORONTO, sobre os 433 textos (TEXTOS1) foi obtido um conjunto de 13.782 termos (CONJ2).

A partir dos critérios de aderência com o tema proposto, sobre o conjunto CONJ2, resultaram seis palavras-chave, a saber: Abandono, Abrigo, Internação, Psicológico, Terapêutico e Vulnerabilidade (CONJ2Limpo).

Desta forma o conjunto de palavras-chave expandido, CONJ3, passa a ser composto por 11 palavras-chave, a saber:

- Medida Protetiva, Medida Socioeducativa, Risco à Saúde, Saúde ECA, Tratamento Saúde (CONJ1- figura 1);

- Abandono, Abrigo, Internação, Psicológico, Terapêutico e Vulnerabilidade (CONJ2 Limpo- figura 1).

Orientando as buscas a partir do CONJ3 foram obtidos 10.279 textos (TEXTOS2). Aplicando os critérios de aderência com o tema proposto (seleção 
sobre os TEXTOS2) resultou em um conjunto com 588 textos (TEXTOS3). Do conjunto TEXTOS3, 86 textos não puderam ser utilizados por não apresentarem os dados suficientes para completar as variáveis, o que resultou em 502 textos adotados para pesquisa. Desta forma a base de dados resultante contempla 502 registros para 25 variáveis.

A partir da tabela 1 é possível verificar a frequência absoluta e relativa dos textos obtidos a partir do uso das palavras-chaves.

Tabela 1 - Frequência absoluta e relativa dos textos encontrados, segundo palavra-chave - 2014

\begin{tabular}{l|r|r}
\hline \multirow{2}{*}{ Palavra-Chave } & \multicolumn{2}{c}{ Frequência } \\
\cline { 2 - 3 } & Absoluta & Relativa \\
\hline Abandono & 27 & 5,4 \\
\hline Abrigo & 9 & 1,8 \\
\hline Internação & 28 & 5,6 \\
\hline Medida Protetiva & $\mathbf{1 8 5}$ & $\mathbf{3 6 , 9}$ \\
\hline Medida Socioeducativa & $\mathbf{9 8}$ & $\mathbf{1 9 , 5}$ \\
\hline Psicológico & 28 & 5,6 \\
\hline Risco à saúde & 29 & 5,8 \\
\hline Saúde ECA & 20 & 4,0 \\
\hline Terapêutico & 6 & 1,2 \\
\hline Tratamento saúde & $\mathbf{3 8}$ & $\mathbf{7 , 6}$ \\
\hline Vulnerabilidade & $\mathbf{3 4}$ & $\mathbf{6 , 8}$ \\
\hline TOTAL & 502 & 100,0 \\
\hline
\end{tabular}

Fonte: Adaptado de Tribunal de Justiça, 2014.

Dada a estratégia de agrupamento a partir destes resultados (Tabela 1) adota-se como Palavra-Chave Agrupada (tabela 2) Medida Protetiva (36,9\%). Medida Socioeducativa (19,5\%), Tratamento saúde $(7,6 \%)$ e Vulnerabilidade $(6,8 \%)$. As demais passam a compor o grupo outras $(29,4 \%)$.

Tabela 2 - Frequência absoluta e relativa dos textos, segundo palavra-chave agrupada - 2014

\begin{tabular}{l|rr}
\hline \multirow{2}{*}{ Palavra-Chave } & \multicolumn{2}{|c}{ Frequência } \\
\cline { 2 - 3 } & Absoluta & \multicolumn{1}{c}{ Relativa } \\
\hline Medida protetiva & 185 & 36,9 \\
Medida socioeducativa & 98 & 19,5 \\
Tratamento saúde & 38 & 7,6 \\
Vulnerabilidade & 34 & 6,8 \\
Outras & 147 & 29,3 \\
\hline TOTAL & 502 & 100,0 \\
\hline
\end{tabular}

Fonte: Adaptado de Tribunal de Justiça, 2014. 
A partir destes resultados pode-se inferir que prioritariamente as demandas convergem para a proteção das crianças e dos adolescentes. E, vale salientar que nos demais testes se utilizou a variável "palavras-chave agrupadas".

Enfim, como resultado sobre o apontamento das situações de não garantia automática do direito à saúde das crianças e dos adolescentes associadas à Medida Protetiva e Socioeducativa se obteve o quadro 2:

\section{Quadro 2: Situações que evidenciam a não garantia automática do direito à saúde}

\begin{tabular}{|c|c|}
\hline Pedido sobre a necessidade de Abrigo & $\begin{array}{l}\text { A internação tem finalidade educativa e curativa. É } \\
\text { educativa quando o estabelecimento escolhido reúne } \\
\text { condições de conferir ao infrator instrumentos } \\
\text { adequados para enfrentar os desafios do convívio } \\
\text { social. Tem finalidade curativa quando a internação se } \\
\text { dá em estabelecimento ocupacional, psicopedagógico, } \\
\text { hospitalar ou psiquiátrico, ante a ideia de que o desvio } \\
\text { de conduta seja oriundo da presença de alguma } \\
\text { patologia, cujo tratamento em nível terapêutico possa } \\
\text { reverter o potencial criminológico do qual o menor } \\
\text { infrator seja portador. }\end{array}$ \\
\hline Pedido sobre a necessidade de Adoção & $\begin{array}{l}\text { É direito fundamental de toda criança e adolescente } \\
\text { ser criado e educado no seio de sua família natural, e } \\
\text { excepcionalmente, em família substituta, assegurada a } \\
\text { convivência familiar e comunitária (art.19, ECA). } \\
\text { Excepcionalmente, portanto, como na hipótese em que } \\
\text { a família natural não seja capaz de garantir direitos e } \\
\text { garantias decorrentes do princípio da proteção integral } \\
\text { (maus-tratos, abandono, dependência a entorpecentes, } \\
\text { orfandade etc.), promover-se-á a colocação da criança } \\
\text { e adolescente, sempre tendo em vista o melhor } \\
\text { interesse destes, em uma família substituta, esta que } \\
\text { compreende três espécies: a guarda, a tutela e a } \\
\text { adoção. }\end{array}$ \\
\hline $\begin{array}{l}\text { Pedido sobre a necessidade de assistência } \\
\text { psicológica/ psiquiátrica }\end{array}$ & $\begin{array}{l}\text { Suporte e acompanhamento psicológico aos pacientes } \\
\text { internados e seus familiares, que abrange todos os } \\
\text { momentos relacionados ao contexto de vida, desde o } \\
\text { diagnóstico de uma doença grave, como nos momentos } \\
\text { mais difíceis de internação prolongada e tratamento. } \\
\text { Se diferencia da requisição de tratamento médico por } \\
\text { ser mais específico ao paciente, ou seja, gera um } \\
\text { sinônimo de continuidade. }\end{array}$ \\
\hline $\begin{array}{l}\text { Pedido sobre a necessidade de Inclusão em } \\
\text { programa de auxílio e orientação à família, à } \\
\text { criança e ao adolescente }\end{array}$ & $\begin{array}{l}\text { A inclusão em programas sociais e de auxílio que } \\
\text { melhor se coaduna àquelas situações, muito comuns, } \\
\text { em que violações dos direitos das crianças e } \\
\text { adolescentes resultam de situação econômico- } \\
\text { financeiras de dificuldade. Trata-se de medida de suma } \\
\text { importância, especialmente naqueles casos }\end{array}$ \\
\hline
\end{tabular}

Inf. Inf., Londrina, v. 23, n. 1, p. 132 - 149, jan./abr. 2018

http://www.uel.br/revistas/informacao/ 


\begin{tabular}{|c|c|}
\hline \multirow{1}{*}{$\begin{array}{c}\text { relacionados à desnutrição, notadamente quando } \\
\text { atingem crianças de tenra idade e que se contam aos } \\
\text { milhares em nossa sociedade. }\end{array}$} \\
\hline $\begin{array}{c}\text { Pedido sobre a necessidade de Orientação, apoio e e } \\
\text { acompanhamento temporários }\end{array}$ & $\begin{array}{c}\text { A orientação apoio e acompanhamento temporários, } \\
\text { que poderá ser realizada pelo Conselho Tutelar ou por } \\
\text { serviço de assistência social, ou, ainda, por serviços } \\
\text { especializados do próprio Poder Judiciário, onde } \\
\text { existam tem aplicação em casos onde não há uma } \\
\text { causa que possa ser incluída dentre as hipóteses de } \\
\text { tratamento médico-psicológico, o onde não exista } \\
\text { omissão imputável aos pais ou responsável. }\end{array}$ \\
\hline Pedido sobre a necessidade de Tratamento médico & $\begin{array}{c}\text { Toda espécie de tratamento especializado para a saúde } \\
\text { integral das crianças e dos adolescentes. Por exemplo: } \\
\text { tratamento médico em regime ambulatorial, hospitalar } \\
\text { e para alcoolismo. }\end{array}$ \\
\hline
\end{tabular}

Fonte: Resultado da pesquisa

\section{CONCLUSÃO}

Este artigo tem como principal objetivo elencar as situações de não garantia automática do direito à saúde de crianças e adolescentes associados à Medida Protetiva e Socioeducativa perante os Estados do Paraná, Santa Catarina e Rio Grande do Sul. Essa não garantia foi evidenciada por meio de 502 textos referentes à Jurisprudências e Acórdãos.

Estas situações estão aliadas às solicitações de abrigo, acompanhamento psicológico e psiquiátrico, orientação, tratamento médico, inclusão em programas de auxílio e de adoção.

A Medida Socioeducativa remete à manifestação do Estado, em resposta ao ato infracional, praticado por menores de 18 anos, de natureza jurídica impositiva, sancionatória e retributiva, cuja aplicação objetiva inibir a reincidência, desenvolvida com finalidade pedagógico-educativa. Tem caráter impositivo, porque as medidas são aplicadas independentes das vontades dos infratores com exceção daquelas aplicadas em sede de remissão, que tem finalidade transacional.

Além de impositiva, Medida Socioeducativa tem cunho sancionatória, em função desta população ter quebrado regras de convivência dirigida a 
todos. E, por fim, pode ser considerada Medida de natureza retributiva, partindo da ideia que é uma resposta do Estado à prática do ato infracional praticado.

Em paralelo à Medida Socioeducativa, tem-se a atuação das Medidas Protetivas, as quais objetivam acolher provisoriamente crianças e adolescentes em situação de vulnerabilidade familiar ou social. O artigo 98 do ECA diz que as medidas de proteção à criança e ao adolescente são aplicáveis sempre que os direitos reconhecidos nesta Lei forem ameaçados ou violados por ação ou omissão da sociedade ou do Estado; por falta, omissão ou abuso dos pais ou responsáveis, ou em razão de sua conduta.

O fulcro da questão é fazer jus ao que o ECA preconiza e preparar essas crianças e esses adolescentes para que sejam reinseridos na sociedade. Um dos fatores que eles mais objetivam é a saúde, pois participam de um meio onde muitas vezes os pais são traficantes ou participam do tráfico, sofrem com doenças e não podem contar com o Sistema Único de Saúde plausível com suas necessidades (BEAL, 2006, p.129).

Os dados analisados oferecem interpretação relevante para se pensar as Políticas Públicas de Proteção à Saúde para crianças e adolescentes, pela trajetória traçada de como os sujeitos estão sendo acompanhados pelo sistema de garantias de direitos.

Em outras palavras, têm-se o amparo e os programas da Administração Pública, Legislação, Processos, Jurisprudências e Acórdão, e fazer valer o direito desses menos favorecidos é o mínimo que se pode oferecer (JACOBINA; COSTA, 2007, p.12).

Uma criança ou um adolescente não pratica um ato infracional porque não tem mais o que fazer, ou ainda, por querer chamar atenção dos pais; pratica $o$ ato por querer uma melhor condição de vida; por querer comer um pão naquele dia. E, sem estudo, sem trabalho, sem dignidade, a única opção que essa pessoa consegue visualizar é praticar um ato infracional (BEAL, 2006, p.127).

Por outro lado, os fins protetores da lei parecem estar sendo exercidos por meio de maior controle social, contudo, apenas quando há visibilidade.

Embora dirigido a todas as crianças, apenas as que possuem menores 
poderes aquisitivos chegam ao Conselho Tutelar vítimas de maltrato e negligência familiar, o que nos leva a pensar que, na inexistência de carência material, não se dá visibilidade a esta questão.

A partir do momento em que se consegue inclinar os olhos para essas crianças e para esses adolescentes que cumprem Medida Protetiva e Medida Socioeducativa se tem condições de elaborar políticas públicas apropriadas para atender às suas demandas e às da sociedade, garantindo a proteção que as leis preconizam (JACOBINA; COSTA, 2007, p.11).

Em decorrência disso é que se possibilita estudar o que a Legislação preconiza em comparação com a realidade dos Tribunais de Justiça, por meio das Jurisprudências e dos Acórdãos.

A partir de então, com base na Recuperação de Termos, a ferramenta PORONTO, embora adaptada obteve a otimização da busca das Jurisprudências e Acórdãos, conseguindo alcançar um dos objetivos específicos que era a identificação do risco a não garantia de forma automática do direito à saúde. A Medida Socioeducativa, a Medida Protetiva, o Tratamento especializado e a vulnerabilidade compõem o cenário da identificação de risco.

Dessa forma se recomenda como trabalhos futuros desenvolver as ferramentas que facilitem a busca e extração dos dados das informações dos textos jurídicos e analisar qualitativamente a judicialização da saúde perante as crianças e os adolescentes.

\section{REFERÊNCIAS}

BRASIL. Lei n. ${ }^{\circ} 8.069$, de 13 de julho de 1990. Dispõe sobre o Estatuto da Criança e do Adolescente e dá outras providências. DOU, Brasília, DF, 16 jul. 1990 e retificado em 27 set. 1990. Disponível em: <http://www.planalto.gov.br/ccivil 03/leis/l8069.htm>. Acesso em: 28 out. 2013.

CONSTÂNCIO, Alex Sebastião; CARVALHO, Deborah Ribeiro; TSUNODA, Denise Fukumi. Construção de uma ontologia para motor de busca jurisprudencial. Revista SODEBRAS, v. 12, n.138, p.115-120, 2017. 
CUBAS, Marcia Regina et al. Mapping and definition of terms used by nurses in a hospital specialized in emergency and trauma care. Revista de Enfermagem Referência. v. 4, n.12, p. 45-54, 2017.

GOMES, Denilsen Carvalho et al. Use of a Computational Tool to Support Content Analysis in Qualitative Research. In: António Pedro Costa, Luís Paulo Reis Francislê, Neri de Souza, António Moreira. (Org.). Computer Supported Qualitative Research. 1ed. Berlin: Springer, v. 621, p. 112-120, 2017

FRAKES, William Bruce; BAEZA-YATES Ricardo. Information retrieval: data structures and algorithms. Michigan: Prentice Hall, 1992.

GRINOVER, Ada Pellegrini; WATANABE, Kazuo. O controle jurisdicional de políticas públicas. 2.ed. Rio de Janeiro: Forense, 2012.

LOPES, Jair Leonardo. Curso de direito penal: parte geral. 2.ed. Sao Paulo: RT, 1996.

PARANÁ. Tribunal de Justiça do Estado do Paraná. Relatórios Estatísticos. Disponível em: <http://www.tjpr.jus.br/site/administracao/prestacao de contas /relatorio anual/2012/RA 2012 TJRGS/pdf/Relatorio 201209 Relatorios Est atisticos.pdf>. Acesso em: 26 out. 2013.

SANTA CATARINA. Tribunal de Justiça do Estado de Santa Catarina.

Relatórios Estatísticos. Disponível em:

$<$ http://www.tjpr.jus.br/site/administracao/prestacao de contas

/relatorio anual/2012/RA 2012 TJRGS/pdf/Relatorio 201209 Relatorios Est atisticos.pdf>. Acesso em: 26 out. 2013.

RIO GRANDE DO SUL. Tribunal de Justiça do Estado do Rio Grande do Sul. Relatórios Estatísticos. Disponível em: $<$ http://www.tipr.jus.br/site/administracao/prestacao de contas /relatorio anual/2012/RA 2012 TJRGS/pdf/Relatorio 201209 Relatorios Est atisticos.pdf>. Acesso em: 26 out. 2013.

ROSA. Alexandre Moraes. Por que a democracia precisa de juízes garantistas? Rio Grande do Sul. 2013.

SILVA, Renata Eleutério da; SANTOS, Plácida Leopoldina Ventura Amorim da Costa; FERNEDA, Edberto. Modelos de Recuperação de Informação e Web Semântica: A Questão da Relevância. Revista Informação \& Informação. Londrina, v.18, n.3, p.27-44, 2013.

ZAHRA, Faruk Mustafa; CARVALHO, Deborah Ribeiro; MALUCELLI, Andreia. Poronto: ferramenta para construção semiautomática de ontologias em português. Journal of Health Informatics, v.5, p.52-60, 2013. 


\title{
INFORMATION RETRIEVAL IN THE IDENTIFICATION OF THE AUTOMATIC NON-GUARANTEE OF CHILDREN AND ADOLESCENT'S RIGHTS
}

\begin{abstract}
Introduction: The assessment of the extent to which the right of the population to health has not been automatically ensured requires consultation to judicial precedents and decisions of higher courts, since there is no systematized data available. Objective: To list the situations of lack of automatic guarantee of the right to health of children and adolescents associated to Protective and Socio-educational measures. Methodology: The strategy of Information Retrieval was adopted in the search for judicial precedents and decisions of higher courts, and based on these texts a database was constructed. Result: Eleven (11) search terms were adopted, resulting in 502 texts related to judicial precedents and decisions of higher courts. Twenty-five (25) variables were listed for the construction of the database. From this analysis, it can be seen that the most common situations of lack of automatic guarantee to the right to health are: psychological/psychiatric assistance, inclusion in programs of assistance and guidance to families, children and adolescents; and medical treatment. Conclusion: These demands indicate that children and adolescents face situations of risk to health, which should not happen, since the right to health is established by law, and therefore should be automatically ensured.
\end{abstract}

Descriptors: Child and Adolescent. Right to Health. Recovery of Information.

\section{RECUPERACIÓN DE INFORMACIÓN EN LA IDENTIFICACIÓN DE NO GARANTÍA AUTOMÁTICA DE DERECHOS DE NIÑOS Y ADOLESCENTES}

\section{RESUMEN}

Introducción: Evaluar como la población no tiene garantizado, de forma automática, el derecho a la salud, exige consulta a las Jurisprudencias y Resoluciones Judiciales, teniendo en cuenta la no disponibilidad de datos sistematizados.

Objetivo: Enumerar las situaciones de no garantía automática del derecho a la salud de los niños y adolescentes asociados a la Medida de Protección y Socioeducativa.

Metodología: Para la búsqueda por Jurisprudencias y Resoluciones Judiciales fue 
adoptada la estrategia de Recuperación de Información y a partir de estos textos fue construida una base de datos.

Resultado: Fueron adoptados 11 términos para la búsqueda, resultando en 502 textos referentes a Jurisprudencias y Resoluciones Judiciales. Fueron enumeradas 25 variables para la construcción de la base de datos. A partir del análisis es posible percibir que las situaciones de no garantía automática del derecho a la salud, que más se destacan son: asistencia psicológica/ psiquiátrica; inclusión en programas de auxilio y orientación a la familia, al niño y al adolescente; y tratamiento médico.

Conclusión: Esas demandas indican que los niños y los adolescentes se encuentran en alguna situación de riesgo a la salud. Hecho que no debería ocurrir, ya que el derecho a la salud es establecido por Ley, no habiendo necesidad de demandas para esos pedidos.

Descriptores: Niño y Adolescente. Derecho a la Salud. Recuperación de Información. 